\title{
Pocket Parks: Urban Living Rooms for Urban Regeneration
}

\author{
Mennatallah Hamdy ${ }^{1, *}$, Rovena Plaku ${ }^{2}$ \\ ${ }^{1}$ Department of Architecture and Urban Design, German University in Cairo, Cairo, 11865, Cairo, Egypt \\ ${ }^{2}$ ILS Institute for Regional and Urban Development, Dortmund, Germany
}

Received November 1, 2020; Revised March 7, 2021; Accepted March 24, 2021

\section{Cite This Paper in the following Citation Styles}

(a): [1] Mennatallah Hamdy, Rovena Plaku, "Pocket Parks: Urban Living Rooms for Urban Regeneration," Civil Engineering and Architecture, Vol. 9, No. 3, pp. 747-759, 2021. DOI: 10.13189/cea.2021.090316.

(b): Mennatallah Hamdy, Rovena Plaku (2021). Pocket Parks: Urban Living Rooms for Urban Regeneration. Civil Engineering and Architecture, 9(3), 747-759. DOI: 10.13189/cea.2021.090316.

Copyright $\bigcirc 2021$ by authors, all rights reserved. Authors agree that this article remains permanently open access under the terms of the Creative Commons Attribution License 4.0 International License

\begin{abstract}
Urban parks are mostly implemented as large green-infrastructural projects exclusive to recreational activities and economies. Currently, $54 \%$ of the global population is urban and is projected to increase to $68 \%$ by 2050 (UN 2012). This entails the need for a more sustainable approach towards food production, movement and overall living together in cities. Micro-scale communal spaces could potentially prompt such goal. They are often most effective when they utilize abandoned or ill-used urban voids; transforming them into pocket parks. This paper frames pocket parks as a potential first step towards both: sustainable urban regeneration, and equal access to public spaces in dense cities. It hypothesizes pocket parks as an answer to economic crisis, food production pressure, run-down communities and the lack of development land for communal spaces. It highlights their key implementation challenges. Also, the influence of communities' contextual needs on pocket parks' size, design, activities and funding is investigated by comparing selected international projects. Reflecting on the Mediterranean context, case studies from Cairo, Egypt and Tirana, Albania are analyzed and room for further implementation is discussed. Finally, the paper concludes with some recommendations to overcome their implementation challenges in commercial city centers and mixed-use residential areas.
\end{abstract}

Keywords Pocket Parks, Urban Transformation, Regeneration, Community Space, Neighborhood Greenery, Small Urban Spaces

\section{Introduction}

Public spaces, green spaces being one of them, have an important impact on cities' quality of life, by creating pleasant microclimates away from traffic noise prompting social interaction. Rapid urbanization and urban population growth have dismissed environmental concerns and the urban quality of life. While the global urban population is expected to increase by $70 \%$ by 2030 , the urban landcover will increase by over $200 \%$; highlighting a serious imbalance between urbanization and population paces [1]. The Mediterranean basin is expected to have the highest percentage of urban land cover (5\%) making it the global biodiversity hot spot [1]. The Mediterranean countries' urban population has more than doubled between 1970 (152 million) and 2010 (315 million) [2]. With urban population increasing, so does the demand for natural resources, including agricultural products [3].

17 Sustainable Development Goals (SDGs) were released by the United Nations in 2015 which would serve as a platform for a sustainable future by 2030. Goal 11 of the SDGs states: "Make cities and human settlements inclusive, safe, resilient and sustainable." Its targets include providing equal access to public spaces to all social classes, ages, genders, and people with disabilities. Such equal access can be guaranteed by providing such public spaces in proximity to residential areas and businesses. The proximity to residential areas would ensure access to elderly people, children and people with disabilities, while the proximity to services and business areas would provide a much-needed break from city noise. 
However, the availability of land to establish open spaces wherever they are needed is challenging ensuring fair access.

Modern grand-approaches towards urbanism have illustrated a great detachment between the urban planners' top-down structuring of spaces and the intimate scale of a community of individuals [4]. In an attempt to fill the gap between the larger city and the human dimension, small-scale projects are gaining more favor in order to give people their rightful place in the design equation. Such micro interventions are accompanied by a level of precision as they customize small-scale solutions on restricted surfaces. On the grander scheme, they are urban planning tools to re-activate the larger urban structure by healing exact spots [5].

\section{Aim and Methodology}

The paper hypothesizes pocket parks as an answer to economic crisis, food production pressure, run-down communities and the lack of development land for communal spaces.

Taking into account the interdisciplinary nature of such spaces, a mixed approach was adopted. The methods used in this study consist of:

- Literature review to draw up and examine key principles on how pocket parks adapt to various urban contexts, mainly dense urban centers and residential neighborhoods with scarce developable land for public use. In addition, the various challenges and crucial practical aspects that could facilitate their implementation.

- Qualitative comparison of selected international projects, comparing the impact of community contextual needs on the pocket parks' size, design, activities and funding. These core aspects (i.e. the comparison criteria) are elaborated in detail in the prior literature review phase of this research.

- Lastly_-, the analytical approach, which reflects on the Mediterranean context. Case studies from Cairo, Egypt and Tirana, Albania are analyzed, and room for further implementation is discussed.

- The paper concludes with some recommendations to overcome their implementation challenges in commercial city centers and mixed-use residential areas.

\section{The Evolution of Pocket Parks' Concept}

Pocket parks replace vacant building lots or unused places that slipped through the real-estate interest, with little patches of landscape [6]. As the name suggests, pocket parks are a form of public space, part of the broader "parks" category. They are referred to by various names in literature, such as mini-parks, vest-pocket parks, or neighborhood parks.

New York, USA is claimed to host one of the earliest forms of mini parks, known as 'the Bowling Green', established in 1733 [12]. The locals wanted a place to play bowl. Therefore, headed by three representatives, they developed a park now located central to New York's business district with an area of 2,000 $\mathrm{m}^{2}$ [7].

The birth of the pocket parks' concept in the US in 1897 can be accredited to the urban reformer Jacob Riis who was the Secretary of the Small Parks Committee. This committee released a statement calling for the turning of every unused corner into a pocket park. Until the Second World War, the concept of Riis remained largely unrealized. Europe's cities, which had passed through rough war events, offered the opportunity to build small parks at less cost than what would have been involved in reconstruction [8].

Professor Karl Linn (1960s-1980s) with his famous concept of "neighborhood commons" further promoted the concept of pocket parks. Consequently, a project to develop a network of pocket Parks in New York, Baltimore, Philadelphia and Washington, was initiated at the middle of the $20^{\text {th }}$ century to enhance urban environments [8]. In 1963, Robert Zion suggested, in an exhibition titled "New Parks for New York", the utilization of pocket parks as small-scale environmental restoration elements in dense urban areas. Paley Park was built in 1967 and is the first 'official' pocket park and has served as the model for pocket parks worldwide [9].

\section{Characteristics of Pocket Parks}

The right to access green spaces is not a topic of just quantitative increase. While urban parks offer opportunities for wide social interaction, pocket parks are more concerned with high-density urban neighborhoods, where they interconnect intimately with their immediate communities. It is this close connection to their locality, along with their small size, which give pocket parks their intimacy. Pocket parks, while small in size, are complex in design, objective and program. Few literatures offer specific design advice or land acquisition techniques to encourage their increase [10]. Since pocket parks are indeed a type of public space, this research perceives that the findings of public spaces can be applied consistently to pocket parks in their given context. The paper analyzes the characteristics of pocket parks according to the dimensions of (1) size and location -as relevant to the urban context-, (2) physical features -looking at various design elements-, (3) potential activities -as triggers of place-making-, and finally (4) possible funding and management schemes ${ }^{1}$.

1While context, design and management have been the most consistent dimensions discussed in the reviewed literature on social life in public spaces, activities have been deemed by the authors as the dimension that actively ties people to the place. 


\subsection{Size and Location}

Goldsteen et al. [11] defined the term 'Pocket Park' as "parks in densely built locations occupying interstitial space between buildings and bounded by sidewalks and walls of existing buildings". They are typically one to three house lots in size or smaller in three basic locations: corner lots, mid-block lots, and through-the-block lots [12]. Their dimensions tend to be proportional to the sense in which they are being designed. Marcus and Francis [38] for example stated that a pocket park could be less than one meter wide $(0.9 \mathrm{~m})$ in major cities like New York and Philadelphia.

To achieve social inclusion and to target areas most in need of green space, due care must be given to the placement and distribution of the pocket parks in the city. By engaging creativity in locating the pocket parks, they can be accommodated in unusual places like roofs, activating building façades with narrow hallways, and vacant or misused sites. In commercial areas, unique opportunities like abandoned infrastructures, old railroads, parking lots, or cars' right-of-way reduction may be present.

Pocket parks, on a city-scale, should be distributed at much closer distances than larger neighborhood gardens and other park-category spaces [13]. Pocket parks should serve a population of about $500-1000$ people at approximately $400 \mathrm{~m}$-radius from all the residences inside the service area (a 10-minute walk). In addition, they should be reachable by both foot and bike, and accessible from 2 to 4 sides from the street, with minimum street frontage of $30 \mathrm{~m}$ to ensure visibility $[13,14]$.

\subsection{Physical Features}

Working together, an array of design decisions and ingredients re-shape 'dormant' spaces, into pleasant social places of pocket parks. The decisions include the choice of furniture -fixed or movable-, the materials used -hard-scape or soft-scape-, types of vegetation, the amount of shading, visibility, control over the weather conditions, possible activities and functions that would take place in that area, and finally, how the place will economically sustain and maintain itself.

A pocket park with natural elements, protected against urban noise and equipped with flexible seats can promote positive social perception of these dormant micro-spaces and their operation as social meeting places. In addition, accessibility and visibility from adjacent streets are vital. The need for an enclosure, visibility and good sitting means that people's ability to relax is directly correlated to their sense of control and safety [15].

Seating elements are an important physical feature that affects the use of parks. Their placement determines the closeness of people and therefore the level of contact [16]. They allow people with shared interests to engage in further interactions while allowing other people to coexist without socializing [17]. When designed properly, even steps and ledges can be used by people to sit. For pocket parks, the focus in seating design should be on functional flexibility rather than overly stylized architectural elements. As a highly flexible solution for seating, moving chairs are recommended.

Playing structures or water elements can be designed around the seats and surrounding paths, allowing a general view of people before deciding to stop. Seating on 'traffic' nodes like the park entrance provides more opportunities to socialize more intensively $[18,19]$.

\subsection{Activities}

The hosted activities depend on the contextual characteristics of the communal place and its potential users' needs [20]. A pocket park may appear in a business district, community center or a residential area. Publicly accessible community places developed with a bottom-up approach enable people to change and edit according to their needs and preferences. Being built for the purpose of promoting active community participation, they expand what is seen as a 'typical' activity appropriate for a public space. They are less focused on consumption and through-movement and more concerned with production and learning [21]. They may serve as children's play areas, relaxing, or talking to friends, having lunch, a courtyard in dense suburban areas or a garden for the community. In addition, these activities can expand to urban agriculture, education, lectures, community kitchens, movie screening, reading...etc. This flexibility in activities creates a distinctive sense of place relevant to their areas as well as a strong sense of ownership. They are not mere gardening projects but aspire towards true self-organized community engagement.

\subsection{Funding and Management}

The ownership scheme entails the funding and maintenance responsibilities. They include:

(A) Privately owned public spaces (POPs): a private investor owns and maintains the public pocket space. This reduces the municipal financial burden and limits municipal control over the space. It offers a win-win situation for the private owner who is encouraged to supply a public space in expensive areas, in return for benefits like obtaining extra development land. Being privately owned, such pocket parks would usually have gates and limited operational hours. (Ex. Paley Park - NY, USA) (John F. Collins Park- NY, USA).

(B) Community ownership: the residents self-organize and apply for permits and initial funding for land acquisition, fences, gates, benches and plants. Once the pocket park is opened, its long-term maintenance is the responsibility of its local users. This entails 
setting up a maintenance schedule with specific tasks for each local member. Maintenance costs can be shared with a town council or community associations. If street vendors are interested in renting in the place, they sign a maintenance contract before allowing them ownership) [22] (Ex. Esta es una Plaza - Madrid, Spain).

(C) Municipal ownership: a complete top-down approach where the government owns the space and is completely responsible for funding and maintaining it. This allows longer hours of public access but limits the local community's sense of ownership and level of involvement in taking care of the space. (Ex. Fałata/Prusa corner Park - Kraków, Poland) (Butterflies garden- Kraków, Poland).

(D) Public-Private Partnership (PPP): the private sector (or a fund-raising partner) does not own the space. Their role, however, could be to raise funds, donate cash funds, materials, or urban furniture in exchange for having their logos displayed in the space. This reduces the financial burdens on the government, while highlighting the social responsibility of the private sector. (Ex. Devil's Teeth Parklet - San Francisco, USA).

The prevalence of a certain ownership scheme depends on the political construct of the city. In Madrid, communal spaces tend to evolve from squatting movements. In Berlin, obtaining a temporary use permit before starting the project is the most likely scenario [21].

\section{Impacts of Pocket Parks}

Pocket parks, with their small size, communicate a level of social intimacy. It is that intimacy that allows them to be open-air "living rooms" [20]. By considering pocket parks as 'urban living rooms,' the character of this space is created and their full potential as 'social places' is unlocked. The dormant spaces transform into outdoor, multi-functional rooms that welcome people of different cultures, ages, genders, knowledge and needs. They trigger social transformation by connecting people to create social activities, prompting an overall urban regeneration process [23].

Municipalities tend to prefer large-scale parks and complex buildings on precise per-determined locations, which tend to be budget intensive. However, research has proven that large-scale projects potentially have less profit and impact than micro-projects. The latter have better capacity to improve the economic, ecological and social reality of a community [20]. Pocket parks provide a number of key potential benefits for the whole community:

- Reinforce a sense of place and better community image: Even the smallest parks offer a sense of place and are a pride to the community. Pocket parks are used for a wide range of social activities. They provide a place of intimacy to meet friends, drink coffee, play and have fun in nature.

- Prompting urban regeneration in dormant/ declining communities: Pocket parks capitalize on void spaces with physical identity but lack activating functions. They turn passive dormant spaces into active ones. They trigger social transformation by connecting people; usually the same people who create and use the pocket park [24].

Safety and security enhancements: Pocket parks provide families and friends of a neighborhood a chance to meet after work or school. In a well-designed and vibrant public space, young families and seniors can relax and exchange knowledge with residents.

- Social Inclusion: Pocket parks can be tools for social and age inclusion programs by allowing social categories like lonely parents, kids, and the elderly, who do not venture outside their direct surroundings, a closer chance at social contact. Children who otherwise might not have easy access to nature have a place in the grass and have a cool breeze in a nice green environment. By integrating agriculture in the local pocket parks, older citizens who would not be able to take care of large lands are supplied with small-scale cheaper agriculture.

- Noise buffer: Pocket parks become buffer zones from the hustle of the city, while encouraging an array of social content to take place not too far from the bustling city that it is buffering.

- A micro-sustainable community: Integrates the topics of sustainability and climate change in daily life, reconciling social consciousness towards the environment and economic sustenance of oneself.

- Protect environmental resources and improve the micro-climate while preserving nature's presence in the city: Green space preservation is an important part of environmental protection. They decrease the urban heat island effect by improving ventilation and ground infiltration [25]. They also regulate air quality by filtering pollutants out of the air while trees help filter out the pollutants of the ground and provide shade for cooling.

- Promoting health and well-being: Activities like urban agriculture make fruits and vegetables more accessible. This engages the local community in a culture of healthy eating and food production creating a micro sustainable community where people cooperate, relax, learn and enjoy; all while producing food. This can trigger a future more sustainable neighborhood lifestyle to cope with climate change and food scarcity 'together'. ${ }^{2}$

2 Research has shown that urban agriculture can be self-sufficient in food production in most of North American metropolitan cities. [39] 
- Increase city biodiversity by infusing it on a neighborhood level: They provide wildlife habitat for not only plants and animals, but also insects and birds (two important species for pollination) putting people in close contact with nature. Such pollination ensures healthy active green cores in dense urban neighborhoods. This can be especially tangible in crop yield from urban agriculture [26]. Urban gardens, with a high variety of plant species and densities, are especially better at the sequestration and storage of $\mathrm{CO}_{2}$; one of the main catalysts of climate change [27].

- Promoting and Supporting local economies: Pocket parks are often hidden within downtown shopping areas and dense residential areas near neighborhood shops, where visitors could stop shopping, for example to buy a snack and a drink while sitting in the park's quiet shade.

\section{Comparative Analysis of International Pocket Parks}

In an attempt to investigate the success of some implemented pocket parks, a comparison (Table 1) is applied between four selected case studies: Paley Park in New York, USA, Prinzessinnengarten in Berlin, Esta es una Plaza in Madrid, and Garden of Butterflies in Krakow, Poland. These projects represent an array of contexts, and thus contextual needs. They also show the effect of the various ownership, funding and maintenance schemes on the social interaction and potential activities in the pocket parks.

The comparison criteria are based on the presented literature review, comparing the projects based on the four key characteristics of: size \& location, physical features, activities, and funding and management. This method underlines the role of the political and social context of cities in the creation of pocket parks. The results can help establish guidelines for creating new pocket parks in the rapidly densifying cities. Also, the analyses can supply general approaches towards their long-term maintenance.

\subsection{Paley Park}

Being one of the earliest, most recognized pocket parks, it is an exemplar reference of adapting pocket parks in the context of a business district. It utilizes "POPs" as a unique solution towards creating such spaces in busy and expensive districts ${ }^{3}$.

The park is surrounded by buildings of various heights from 3 sides with a gate on the 4th side which allows limited operational hours imposed by the maintaining

3 New York has 530 privately owned public spaces which are lawfully accessible to the public [40]. owner. The enclosing walls have been incorporated in the design using ivy covering and a characteristic water wall. The park is completely visible and accessible from a highly frequented street, from which it manages to separate itself via 4 elevated steps. As for the seating, movable chairs and tables allow users flexibility of use. The ground is predominantly hard paved with natural elements in the form of trees and ivy-covered walls.

\subsection{Prinzessinnengarten}

It was launched 2009 as a pilot project by the 'Nomadic Green' NGO at Moritzplatz, Belin. The site had been a car-dominated non-place, a wasteland where trash piled. Locals and activists answered an open call to participate in the cleaning and building process. The spatial configuration was spontaneously created when the cleaning party sorted through trash and whatever could be used was discussed and placed somewhere in the space [28].

The land is leased to the NGO to create a mobile urban farm, where portable pots are used to grow fresh healthy food. Being owned and maintained by the NGO, the founders experimented with putting cooperative urban gardening and learning into an economic cycle. Instead of fighting capitalism, they worked with it reconciling social consciousness and economic gain. The pocket park generates income from the café which turns grown food into meals, educational workshops, consultation services, guided tours, and donations. The founders became managers and profiter from the place while locals gained their leisure interactive place. Hiring 11 employees, the park offered job opportunities and weekly meetings with locals involving them in decisions related to hosted activities and events [29].

Prinzessinnengarten attracts a wide range of audience. In addition to the local community, visitors come from a distance to visit the café and participate in the garden activities and workshops. Proximity to the Moritzplatz metro station might have facilitated that to an extent.

\subsection{Esta es una Plaza "This is a Public Space"}

It contains a space of $1200 \mathrm{~m}^{2}$ in Lavapiés, a comparatively low-income district in central Madrid with the largest population of immigrants. The idea was first conceived in 2008 during a workshop at the nearby cultural center. In 2009 it was turned into a landscaped, quiet and pleasant place through successive interventions and activities [21].

It uses the plot free of charge but has a contract of temporary use for 5 years, with the possibility of extension. Instead of allowing private commercial or residential development, the community took control of the land and rebuilt it as a multifunctional park. It offers classes on creating renewable energies such as biogas and 
geothermal energy. It operates using a participatory culture and knowledge exchange of the organizations, groups, universities, foundations and neighbors that share it. It's only open on Sundays and sunny days. It is also enclosed by brick walls decorated by local artists with fruit trees and garden plots, a playground, self-made structures and creations [30].

\subsection{The Garden of Butterflies}

It was opened in 2017 in Kraków, Poland, as part of a municipal initiative to create more mini parks. During this period, a group of students took the initiative to create a green area that integrates the local community. It is owned and maintained by the municipality. It is in a mixed-use neighborhood and covers an area of $554 \mathrm{~m}^{2}$. It is bordered by a historical residential building with an active ground floor. It consists of a little square with a road that leads along heavy wooden benches which are permanently fixed in their position. Insect hotels -mostly for butterflies- are the defining characteristic and purpose of the Park. This pocket park focuses on bioactive surfaces with different plant species to create insect-friendly conditions. Wooden elements for interactive games were implemented for younger users. Being surrounded by multifunctional buildings contributes towards the great number of users and is open to residents and visitors of Kraków. However, insufficient parking spaces in the park's vicinity have led drivers to park on the pavement surrounding the park. Thus, creating a pedestrian barrier and blocking the view from street level [31].

\subsection{Reflections}

Comparing these case studies (Table 1), one starts to reflect on the flexible nature of pocket parks; they can accommodate a wide range of agendas while putting social interaction at the core. In the USA, the POPs scheme made such social places accessible for the various users of the business district. Gates maintain the investor's right to close it for limited times when needed. The predominant hard paving and movable furniture facilitate maintenance while allowing flexibility for users. In addition, focus on water features for urban climate regulation. The Poland case is Municipally owned by Kraków making it accessible all day. While the main target users are the local community, it is still available for the whole of Kraków. Contrary to Paley Park, ecological land covering is predominant focusing on community biodiversity. On the other hand, both Esta es una Plaza and Prinzessinnengarten are temporarily leased with possibility for lease extension. They are publicly available and have examples of DIY urban design. The users themselves installed furniture and structures on site, much like one would do in their own home, in a layout that allows a range of uses, from open-air screenings to urban gardening. Both locations are specifically centered on group learning and development, further emphasizing on intimacy and place-making. Prinzessinnengarten incorporates biodiversity and food production in the recreational concept and finds the balance between formal and informal structures of creating such places. While Esta es una Plaza highlights the neighborhoods' role in building and valuing resources while creating new relationships between the community members.

\section{Potentials in the Mediterranean Context}

Some Mediterranean countries have realized successful pocket parks associated with strong community social movements. These include Esta es una Plaza (Madrid, Spain), Piazza Venezia Pocket Park (Rome, Italy) and Promenade de la Petite Ceinture (Paris, France). However, for the most part, they are still a rare find in a region whose green cover is on the decrease in favor of rapid development and continuous urban densification. The following part focuses on Cairo, Egypt and Tirana, Albania as two cities that suffer from continuous densification and gentrification. The current municipal attempts to introduce greenery in the smaller neighborhood scale will be explored and critiqued. Further, a positive example of a pocket park in each city will be discussed as well as reflections on further potentials for them to exist and improve the socio-ecological reality of the two cities. 
Table 1. Comparison of International Case Studies

\begin{tabular}{|c|c|c|c|c|c|c|}
\hline \multicolumn{3}{|c|}{ CRITERIA } & \multicolumn{4}{|c|}{ THE INVESTIGATED PARK } \\
\hline & & & $\begin{array}{l}\text { Paley Park - } \\
\text { New York }\end{array}$ & $\begin{array}{c}\text { Prinzessinnengarten } \\
\text { - Berlin }\end{array}$ & $\begin{array}{c}\text { Esta es una } \\
\text { Plaza - } \\
\text { Madrid } \\
\end{array}$ & $\begin{array}{c}\text { Garden of } \\
\text { Butterflies - } \\
\text { Krakow } \\
\end{array}$ \\
\hline \multicolumn{3}{|c|}{$\begin{array}{c}\text { Paley Park:@Zion and Breene } \\
\text { Associates } \\
\text { Prinzessinnengarten: } \text { CMarco Clausen } \\
\text { Esta es una Plaza: } \text { Cmoderno \& } \\
\text { Castizo } \\
\text { Garden of Butterflies: } \text { CRita Labuz }\end{array}$} & 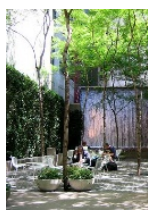 & $\lim ^{2} \operatorname{los}^{2}$ & 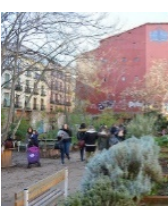 & $\operatorname{lin}_{2}=1$ \\
\hline \multirow{4}{*}{$\begin{array}{l}\text { Size and } \\
\text { Location }\end{array}$} & Area $\left[\mathrm{m}^{2}\right]$ & & $390 \mathrm{~m}^{2}$ & $5556 \mathrm{~m}^{2}$ & $1200 \mathrm{~m}^{2}$ & $554 \mathrm{~m}^{2}$ \\
\hline & $\begin{array}{l}\text { Location } \\
\text { typology }\end{array}$ & & Mid-block & Corner & $\begin{array}{c}\text { Main side } \\
\text { street }\end{array}$ & Main side street \\
\hline & Urban context & & $\begin{array}{l}\text { Business } \\
\text { district }\end{array}$ & $\begin{array}{l}\text { Mixed Use } \\
\text { Residential }\end{array}$ & $\begin{array}{l}\text { Mixed Use } \\
\text { Residential }\end{array}$ & $\begin{array}{l}\text { Mixed Use } \\
\text { Residential }\end{array}$ \\
\hline & Urban fabric & & $\begin{array}{l}\text { Business, } \\
\text { service, } \\
\text { housing }\end{array}$ & $\begin{array}{l}\text { Business, service, } \\
\text { housing }\end{array}$ & $\begin{array}{l}\text { Business, } \\
\text { service, } \\
\text { housing, art, } \\
\text { accommodati } \\
\text { on }\end{array}$ & $\begin{array}{l}\text { Business, } \\
\text { service, } \\
\text { housing, art, } \\
\text { sports, } \\
\text { education }\end{array}$ \\
\hline \multirow{7}{*}{ Physical Features } & \multirow{2}{*}{$\begin{array}{l}\text { Materiality of } \\
\text { ground cover }\end{array}$} & $\begin{array}{l}\text { Hard-paved } \\
\text { surface }\end{array}$ & $\mathrm{X}$ & & & \\
\hline & & Green surface & & $\mathrm{X}$ & $\mathrm{X}$ & $\mathrm{X}$ \\
\hline & \multirow[b]{2}{*}{ Urban furniture } & Permanent & & & & $\mathrm{X}$ \\
\hline & & $\begin{array}{l}\text { Seasonal } \\
\text { (movable) }\end{array}$ & $\mathrm{X}$ & $\mathrm{X}$ & $\mathrm{X}$ & \\
\hline & \multirow{2}{*}{$\begin{array}{l}\text { Terrain } \\
\text { elements }\end{array}$} & Water & $\mathrm{X}$ & & & \\
\hline & & Trees & $\mathrm{Y}$ & $\mathrm{Y}$ & Y & $\mathrm{Y}$ \\
\hline & Gates (no.) & & 1 & 1 & 1 & $\begin{array}{c}\text { No surrounded } \\
\text { walls }\end{array}$ \\
\hline \multirow[t]{2}{*}{ Activities } & Activities & & $\begin{array}{c}\text { Seating, } \\
\text { eating, } \\
\text { socializing }\end{array}$ & $\begin{array}{l}\text { Seating, eating, } \\
\text { socializing, } \\
\text { educational, urban } \\
\text { gardening }\end{array}$ & $\begin{array}{l}\text { Seating, } \\
\text { eating, } \\
\text { socializing, } \\
\text { educational, } \\
\text { urban } \\
\text { gardening }\end{array}$ & $\begin{array}{l}\text { Seating, } \\
\text { educational, } \\
\text { recreating } \\
\text { habitat for } \\
\text { butterflies }\end{array}$ \\
\hline & $\begin{array}{l}\text { Diversity of } \\
\text { users }\end{array}$ & & $\begin{array}{l}\text { Office } \\
\text { workers, } \\
\text { Tourists, } \\
\text { Shoppers }\end{array}$ & $\begin{array}{l}\text { Locals, Workers, } \\
\text { Visitors, Tourists }\end{array}$ & $\begin{array}{l}\text { Locals, } \\
\text { Scholars, } \\
\text { NGOs }\end{array}$ & Locals, Visitors \\
\hline \multirow{7}{*}{$\begin{array}{l}\text { Funding and } \\
\text { Management }\end{array}$} & Ownership & & POP & Public Space & Public Space & Public Space \\
\hline & Project initiator & & $\begin{array}{l}\text { Private } \\
\text { entities }\end{array}$ & NGO, Volunteers & $\begin{array}{c}\text { NGO, } \\
\text { Volunteers }\end{array}$ & $\begin{array}{l}\text { University } \\
\text { students and } \\
\text { Locals } \\
\end{array}$ \\
\hline & $\begin{array}{l}\text { Community } \\
\text { engagement }\end{array}$ & & Limited & $\mathrm{X}$ & $\mathrm{X}$ & Limited \\
\hline & Opening hours & & Limited & Limited & Limited & $24 / 7$ \\
\hline & $\begin{array}{l}\text { Management } \\
\text { actors }\end{array}$ & Community & & $\mathrm{X}$ & $\mathrm{X}$ & $\mathrm{X}$ \\
\hline & & Private investors & $\mathrm{X}$ & & & \\
\hline & & Municipality & & & & $\mathrm{X}$ \\
\hline
\end{tabular}

\subsection{Cairo, Egypt}

Challenge: Egypt faces a constant struggle of interests between the municipality and people regarding public spaces. Questions of ownership, governance and the scope of individual rights to that space arise. In its capital, Cairo, cars are trespassing on pedestrians, concrete is triumphing over green, and different social groups are fighting for their place in the growing city. Cairo is an important economic and cultural center of the country. It is also the main destination of internal migration from rural areas and smaller cities in search for jobs, education and better living standards. This has resulted in the city's overpopulation, pollution. Pressuring demand for housing has led to outwards urban encroachment over productive agricultural landscapes losing the country over 400,000 
feddans over the last 40 years [32]. In addition, over-densification inside cities has led to the gradual disregard of social green spaces and the emergence of informal settlements.

Initiative: The 'Go Green' initiative, launched Jan 2020 by the Ministry of Environment, aimed at cutting GHG emissions, adapting to climate change and maintaining biodiversity in cities. The initiative started by planting trees in Heliopolis neighborhood with active participation of NGOs. However, there is a clear disconnection from current car-oriented developments as the neighborhood's green areas and pedestrian routes were soon overtaken by bridges claiming to fix the city's traffic problems (Fig. 1).

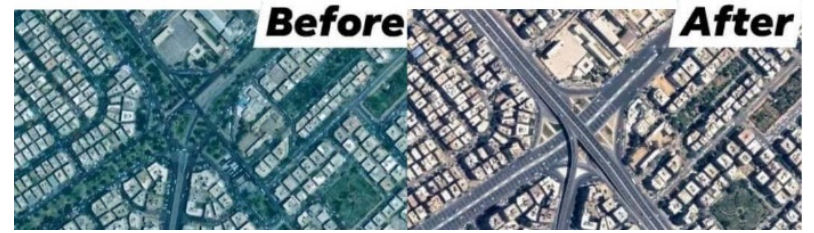

Figure 1. The great disparity between the Go Green environmental initiative and the actual transportation development plans. CGoogle Earth

City Center Interventions: On the bright side, successful pocket parks can be found in the city's downtown. Downtown Cairo's image has been regenerated through by transforming its back alleys and in-between spaces into a network of pedestrianized routes. This has been done either informally by locals and users or officially through municipal initiatives. A wide range of activities has been incorporated in these hidden spaces, with acute focus on retail, cafes, galleries and art spaces. The predominant materials are hard paving with controlled incorporation of greenery and seating. One successful example is the Kodak Passageway which was developed in a bottom-up approach and funded by a foreign donor [33] (Fig 2).
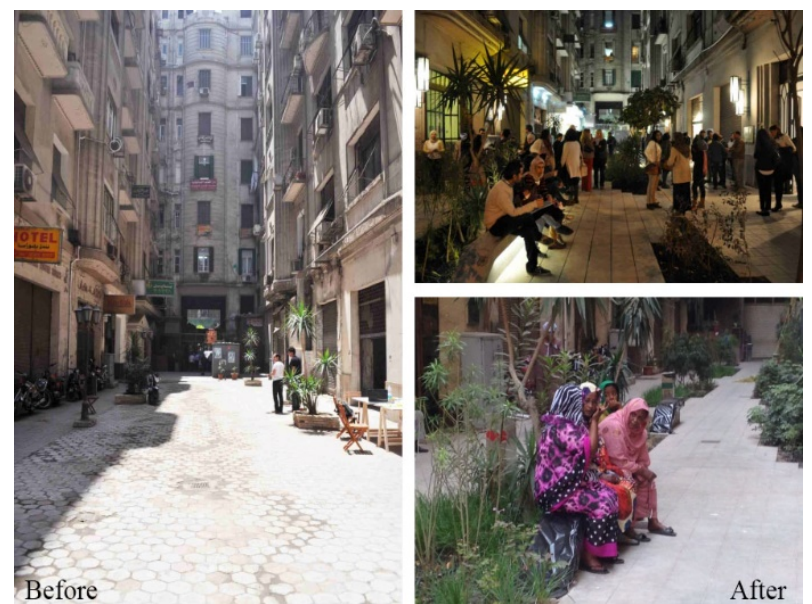

Figure 2. "Kodak Passageway" by Cluster Before and After Transformation (C) Cluster Mapping Initiative

Low-Income Communities Potential: While Downtown Cairo has successful pocket spaces, the new residential areas do not. Reacting to Cairo's growing informal settlements, Egypt has been mass-producing social housing developments as satellite desert cities to relocate the informal inhabitants. However, these developments have been criticized for their lack of human scale, detachment from the inhabitants' social needs and loss of social ties. Looking at 'Al-Asmarat' as an example of these developments, one can see ample potential for pocket parks to replace the overwhelming hard-paved spaces between the buildings. By incorporating urban agriculture and shading trees, such hard-paved isolated communities could engage in a movement of social solidarity oriented towards food production. Most of the informal settlers are from rural origins and have the habit of keeping livestock. They would be able to exchange knowledge and turn such voids into productive urban farms. In the process, they would be able to meet their basic need for food security while also earning additional income, while still achieving biodiversity and better climate conditions (Fig 3).

Recommendations: Given the tension in interest between the municipality and the public regarding public spaces, an appropriate funding scheme would be the POPs or Community organizations. Such schemes fit into the city's capital driven schemes while maintaining a level of social consciousness and decrease the municipality's responsibility and financial burden. This allows more freedom and flexibility for the space, and more room for experimentation and user-participation in the design and implementation.

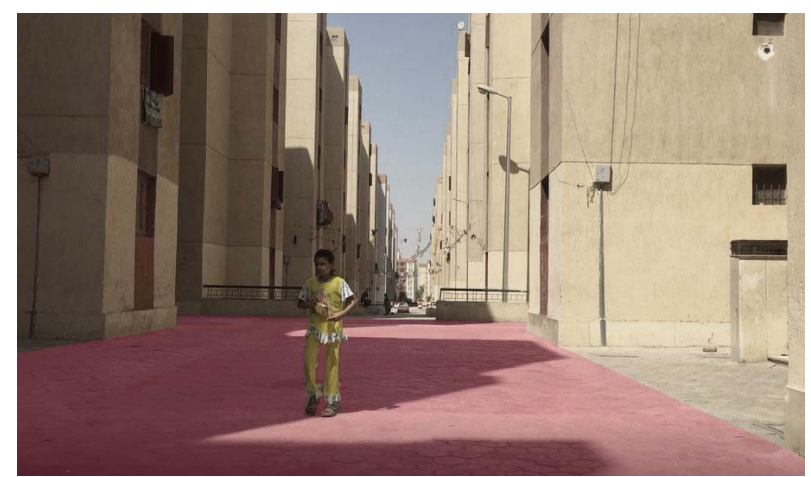

Figure 3. Al-Asmarat Social Housing Development (C) Yara Galal

\subsection{Tirana, Albania}

Challenge: Albania's capital, Tirana has seen rapid growth in the last few years, leaving unused voids whether intentionally or not. Though the city has a large green area (Tirana's Grand Park), it isn't reachable for the whole city's citizens and the requirements of people in highly dense neighborhoods cannot be met. The city's public spaces, which mostly exist in the city's center, lack hierarchy. The interrelation of existing parks with a network of green corridors, sidewalks, street trees and waterways, is often absent. The fall of communism has 
brought a total change of public spaces, which has been one of the city's most problematic issues ever since. This is reflected in their negligence, car invasion, and privatization. In such context, the notion of pocket parks appears to be the "light at the end of the tunnel" where the city can still hope to find and transform the void spaces for the good of its inhabitants.

Initiative: This has been reflected in the recent Green City Action Plan (GCAP) abbreviated as TR030, which aims at adding more greenery at the neighborhood scale in the form of pocket parks, promising a $20 \%$ increase in green spaces. The GCAP aims to create five new 500 $\mathrm{m}^{2}-10,000 \mathrm{~m}^{2}$ pocket parks by 2030 . Eventually, TR030 and GCAP are unable to indicate whether or how the minimum $9 \mathrm{~m}^{2}$ per capita green area will be reached. TR030 only promises adding a total of 2 million trees in the city, while GCAP does not calculate the extent to which the proposals meet the statutory requirements.

Aside from the ineffective practices of public officials, there is no evidence of grassroots initiatives by citizens to get involved in their neighborhoods. Explanations for lack of community involvement include citizens' lack of trust in the effectiveness of participation, low confidence in public institutions to make proposals, etc. [34]. The lack of interest in providing adequate knowledge, combined with the passivity of the community, result in a relatively low level of public involvement [35]. Nonetheless, recently the local population seems inclined and eager to engage in the development of public spaces in the vicinity of their residential blocks.

Successful Interventions: On the bright side, between September 2014 and January 2015, the development of public places with community participation in mind has been achieved successfully in Tirana through the transformation of a pocket space close to "Pallati me Shigjeta" neighborhood (fig. 4). The pocket is surrounded by high buildings looking down on it (fig. 5) facilitating the sense of community and a potentially higher interest in maintaining it. The path is very narrow but located near a high-traffic street that could be used for marketing. The success of the park stems from the neighborhood's maintenance of the park as well as being surrounded by small businesses that serve the residents as well as visitors of various ages and categories, including students from a nearby high school.

Co-PLAN Institute for Habitat Development in collaboration with the Municipality of Tirana and the residents took the initiative to help the locals improve their neighborhoods. The redesign of the space was carried out by field experts in collaboration with the local community after multiple and regular meetings. International and local donors invested in this project as well as students and professionals who invested their time to make this project successful.

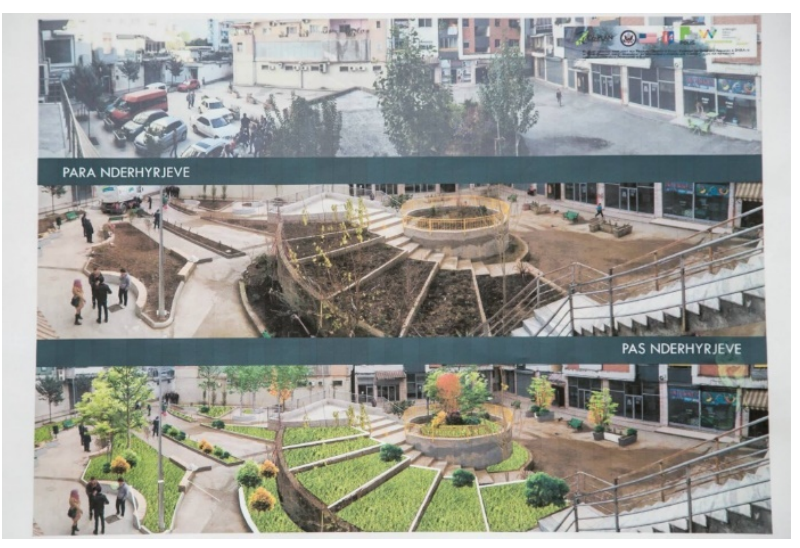

Figure 4. "Pallati me shigjeta" Pocket Park Before and After Transformation (C) Co-PLAN

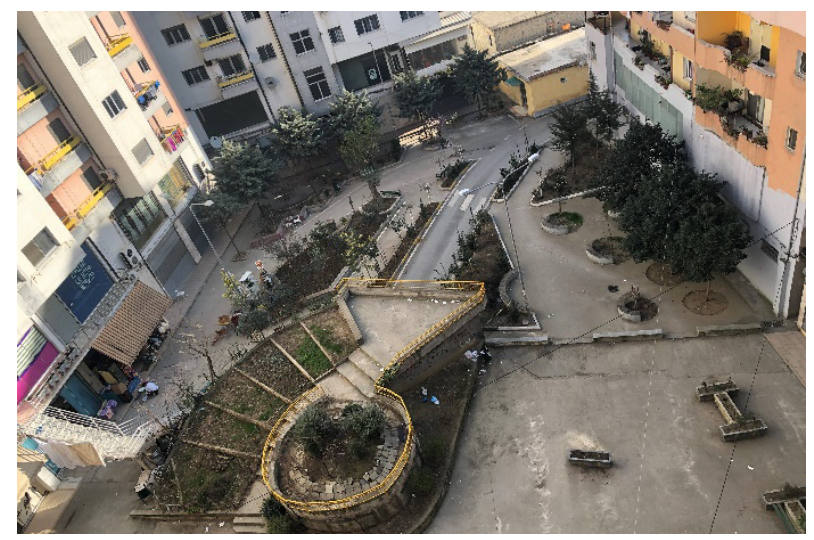

Figure 5. "Pallati me shigjeta" pocket park today @Rovena Plaku

\section{Conclusions and Recommendations}

\subsection{Contextual Flexibility, Impact \& Challenges}

Cities now have the responsibility, not only towards conserving natural resources, but also towards creating green ecological centers in the concrete jungles that we have created. Pocket parks are multidisciplinary social places that offer layers of services (impacts) which include: maintaining a living ecosystem in urban settings, improving safety, promoting social and gender inclusion, and providing an attractive medium for economic establishment and urban food production. Infusing such concepts in the micro urban context facilitates socio-ecological integration, making urban sustainability more approachable and materialized in our daily lives [36].

Pocket parks are contextually-flexible spaces that capitalize on the hidden potentials of leftover urban spaces. They are not concerned with grand sizes, but rather purpose. They target the intimate neighborhood scale and call for democratic communities with inclusive social places of knowledge exchange, productivity and social solidarity. 


\section{- Contextual Challenges of Pocket Parks:}

While they are easy to build, without practical design, community support, usage and maintenance, pocket parks can easily deteriorate [24]. The reviewed literature underlined 'the design of activities in such compact spaces' and 'the long-term funding and maintenance' as their most significant challenges. It also showed a gap in addressing 'practical design and funding aspects' to promote pocket parks' increase [10].

The paper investigated how pocket parks can adapt to and answer the range of contextual needs of the two urban contexts: dense commercial city centers and dense mixed-use residential neighborhoods. It looks for the most appropriate design of activities and funding schemes to capitalize on the potentials of each context (the qualitative analysis in table 1).

The international case studies (point 6) reflect the adaptability, impacts and transformative potential of pocket parks, by showing how effective they can be in:

1. Providing public spaces in dense expensive contexts like commercial down-town areas (Paley Park)
2. Reconciling capital interest in profit and the need for social ties in culturally-diverse communities (Prinzessinnengarten)

3. Educating and involving people in sustainable topics like clean energy production (Esta es una Plaza)

4. Attracting biodiversity to residential neighborhoods (Garden of the Butterflies)

5. Community engagement and participatory planning (Prinzessinnengarten, Esta es una Plaza, Butterflies Garden)

\subsection{Contextual Recommendations of Pocket Parks}

Their most recommended (and common) location is close to frequent pedestrian traffic, for visibility and user-attraction. However, the other aspects change by context; especially the desired activities and their associated design, and the most appropriate funding and maintenance scheme. The table below (table 2) highlights some recommendations to consider when adapting pocket parks to different urban contexts.

Table 2. Contextual Recommendations for Pocket Parks

\begin{tabular}{|c|c|c|c|}
\hline & & Commercial City Centers & Mixed-Use Residential Areas \\
\hline \multirow{2}{*}{ Context } & $\begin{array}{c}\text { Urban Context } \\
\text { Challenges }\end{array}$ & $\begin{array}{l}\text { Expensive land value } \\
\text { Over densification }\end{array}$ & Easy to build but hard to maintain \\
\hline & $\begin{array}{l}\text { Highlighted } \\
\text { Potential* }^{*}\end{array}$ & Quietness amidst the city noise & $\begin{array}{c}\text { Promotes community engagement and eco-social } \\
\text { interaction }\end{array}$ \\
\hline \multirow[b]{2}{*}{$\begin{array}{l}\text { Recommendations } \\
\text { Funding and } \\
\text { Maintenance } \\
\text { Challenge }\end{array}$} & $\begin{array}{l}\text { Recommended } \\
\text { ownership } \\
\text { Schemes }\end{array}$ & Privately-owned public spaces (POPs) & $\begin{array}{c}\text { Depending on the existing participatory culture: } \\
\text { Community ownership } \\
\text { Municipality ownership } \\
\text { Public Private Partnerships (PPPs) }\end{array}$ \\
\hline & $\begin{array}{c}\text { Effect of the } \\
\text { Recommended } \\
\text { Schemes }\end{array}$ & $\begin{array}{c}\text { Promote the Corporate's Social } \\
\text { Responsibility. } \\
\text { The private sector becomes an active player in } \\
\text { the social life. } \\
\text { Create a win-win situation for the owning } \\
\text { company (tax reduction, promotion or } \\
\text { advertisement, etc.) } \\
\text { Private sector becomes responsible for } \\
\text { maintenance cost. }\end{array}$ & $\begin{array}{l}\text { Community ownership has the maximum potential } \\
\text { for community engagement. } \\
\text { Municipality ownership reduces maintenance } \\
\text { responsibilities of the community. } \\
\text { The private sector becomes an active player in } \\
\text { social life by funding the space in exchange for } \\
\text { advertisement opportunities. }\end{array}$ \\
\hline \multirow{4}{*}{$\begin{array}{l}\text { Recommendations } \\
\text { Designed Activities }\end{array}$} & Target Groups & Tourists, Shoppers, Professionals & Nearby Residents (all ages and groups) \\
\hline & Activities & $\begin{array}{l}\text { 1- Multi-functions are challenging due to the } \\
\text { wide range of user backgrounds and their } \\
\text { temporality (no fixed users for the space) } \\
\text { 2- Neutral/ common activities that can appeal } \\
\text { to a wide audience: } \\
\text { Gathering, Relaxing, Reading, Lunch breaks }\end{array}$ & $\begin{array}{l}\text { 1-Multi-functions that depend on the users' needs. } \\
\text { The appropriate activities can be decided using the } \\
\text { participatory approach with the locals. } \\
\text { 2-Interacting/socializing/sustainable activities: } \\
\text { educational activities, productive activities like } \\
\text { urban gardening, recreational, small event space, } \\
\text { play areas for children, spaces for relaxing or } \\
\text { meeting friends, taking lunch breaks, etc. }\end{array}$ \\
\hline & & Compact & More flexible \\
\hline & $\begin{array}{l}\text { Design } \\
\text { Recommended } \\
\text { Design element } \\
\quad \text { (reason) }\end{array}$ & $\begin{array}{c}\text { Movable seating elements (freedom for users } \\
\text { to edit the space as they need }+ \text { easier to } \\
\text { replace) } \\
\text { Hard-scapes for flooring (easier maintenance) } \\
\text { Overhead trees (noise buffers }+ \text { shading) } \\
\text { Lighting elements (safety) } \\
\text { Water elements (for climatic comfort) }\end{array}$ & $\begin{array}{c}\text { Movable seating elements (freedom for users to } \\
\text { edit the space as they need }+ \text { DIY Design) } \\
\text { Natural/ Permeable flooring (attract animals and } \\
\text { birds and prevent runoff) } \\
\text { Overhead trees (noise buffers }+ \text { shading) } \\
\text { Lighting elements (safety) } \\
\text { Playground for the children (age inclusive) }\end{array}$ \\
\hline
\end{tabular}




\section{- Ownership Schemes}

Ownership schemes reflect funding and maintenance responsibilities. The appropriate scheme for each urban context depends on the targeted level of engagement of the private sector, public sector and local community. For instance, privately owned public spaces (POPs) would be the most beneficial in areas with high property value like commercial city centers.

On the other hand, community ownership permits the most participation in design and implementation allowing locals to take ownership of, and pride in their local community. It depends on the community's ability to self-organize their volunteering individuals to manage and maintain the area. This can be a challenge in areas with low participatory culture or constantly changing users (like commercial centers). Hence, it works better for residential or mixed-use areas where a stable local community exists.

For the residential areas, community ownership, municipality ownership and public-private partnership (PPP) can all be beneficial. While municipality ownership puts all financial and maintenance burdens on the local government, (PPP) reduces the local municipality's financial burden by introducing a private partner or a non-profiting fund-raising partner. Such partner oversees the development and initial funding of the space while retaining further management and maintenance responsibilities to the owner (municipality). In the end, the ownership scheme does not matter as long as the space is allowing local users freedom and integrating them in the design and decision of activities.

\section{- Design and Activities}

Design and activities depend on the target users of the space. High-pedestrian commercial centers entail a wide range of temporary users like shoppers, tourists, and professionals on their lunch breaks. For that reason, highly-specific community-engaging activities are not recommended, but rather common social activities like sitting, eating, reading, gathering and relaxing...etc. In such dense areas of expensive land values, pocket parks' true transformative power lies in providing intimate social spaces, presenting a quite ambiance away from traffic noise. The design becomes more focused on flexibility (ex. light-weight movable seating elements) and ease of maintenance (ex. Easy-to-clean surfaces and low maintenance greenery). Also, bottom-up approaches might be challenging but wide scope surveys may help decide the appropriate location for the pocket park.

For residential areas, multi-functions work best. The challenge lies in finding the right balance of activities that appeal to the community members without overcrowding the space or losing intimacy. The design needs to be flexible enough to evolve with the ever-evolving community needs. Bottom-up participation of users becomes essential as they are the most familiar with these spaces. Allowing them to build objects and materialize activities that they think can benefit the community engages them in a gradual process of place-making of their open-air social living room.

\subsection{Case Studies}

The Mediterranean case studies in Cairo and Tirana have similar issues of municipal tension when it comes to public space ownership. Also, similar potential for pocket parks to infiltrate the dense sprawling cities bring social spaces and greenery to the local nationhood scale. Together the two cities represent case studies in city centers and residential neighborhoods as well as potential for low-income peripheral areas (fig 6); highlighting the different challenges and needed actions.

\section{Tirana}

In the Tirana case study, claiming land for pocket parks was strongly linked to finding a car solution. In a society where the car remains the quickest way to travel inside the city, the idea of transforming the car park to a pocket park was not easy. In this regard, it is important for local governments to develop an efficient and trustworthy public transport system, as providing a reliable alternative to cars is an important step to change the city's mindset.

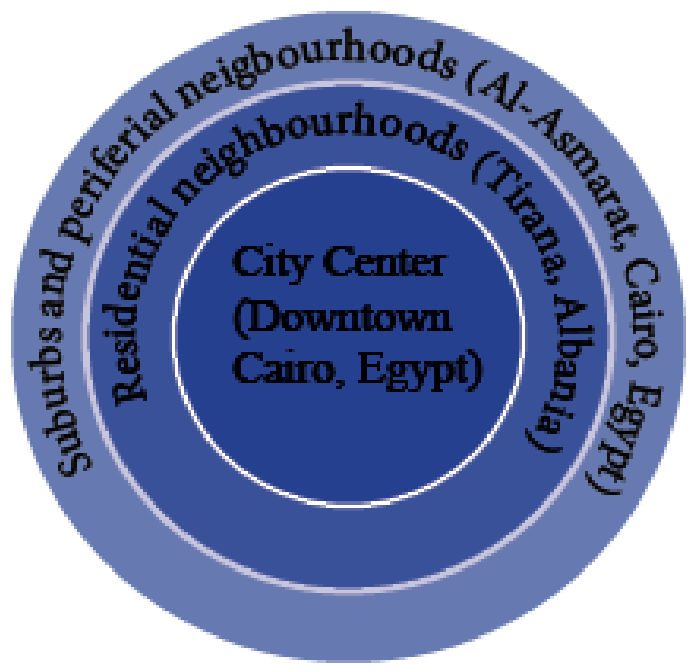

Figure 6. Case studies' urban contexts

While there is a growing interest in participatory planning within communities, the municipality needs to provide an over-view of how to best incorporate the existing potential spaces in a green-network to achieve maximum ecological and social impact at less cost than that of big city gardens. The living conditions of people are dissimilar and so are their problems. Those who live in small apartments with no balconies or gardens are going to be more challenged than those who live in big outdoor homes. For example, the first group more interested in creating, maintaining and enjoying the pocket parks. 


\section{Cairo:}

In Cairo, grand public spaces tend to suffer decline and form socially segregated contexts [41]. Pocket parks, working on the more cohesive neighborhood scale, could promote social inclusivity and solidarity. The current favoring of cars over pedestrians and green areas is turning the city into a sequence of through fares with no opportunity to pause and relax.

The current relocation of Downtown Cairo's pivotal administrative facilities to the new capital has permitted the re-focus on the social life and exploration of its alleys and narrow corridors. Despite having a funding partner, the participatory model of Kodak Passageway took over 2 years of negotiating with the users and the municipality before implementation. In contrast, other municipally-initiated corridors were much faster but lacked the user participation.

The mass social-housing developments are almost void of greenery and proper social gathering spaces. Pocket parks can capitalize on the knowledge of the originally-rural inhabitants through community gardening and urban agriculture. Such activities complement the locals' culture of raising poultry and can provide extra income, food sufficiency, biodiversity and passing of knowledge to the children.

\subsection{Closing Remarks}

As the title of this paper implies, pocket parks have the potential to be an extension of one's home. They can become open-air community homes that capitalize on the hidden potentials of disused spaces. By targeting a specific group of people who use, edit and care for the place, they promote new social links and a more positive attitude towards social spaces. The activities appropriate for pocket parks are whatever activities that satisfy the community needs. Such functional flexibility and intimacy turn them into urban social living rooms; differentiating them from typical parks and their associated grand recreational activities.

Though various ownership schemes have been discussed in this paper, it is important to highlight that the true issue is not about 'who owns the space' but rather 'how much freedom does the community have in the space' and 'how involved are they in the creation and upkeeping'.

\section{REFERENCES}

[1] Elmqvist, T., Fragkias, M., Goodness, J., Güneralp, B., Marcotullio, P. J., McDonald, R. I., Parnell, S., Schewenius, M., Sendstad, M., Seto, K. C., \& Wilkinson, C. (2013). Urbanization, Biodiversity and Ecosystem Services: Challenges and Opportunities. Springer Publishing. ISBN 978-94-007-7088-1. DOI 10.1007/978-94-007-7088-1
[2] Fabres, J., Kurvits, T., Nilsen, R. R., Pravettoni, R., \& Tundi Agardy. (2012). State of the Mediterranean Marine and Coastal Environment. GRID-Arendal and Sound Seas. https://doi.org/10.13140/RG.2.1.3013.2648

[3] Millennium Ecosystem Assessment (2005). Ecosystems and Human Well-being: Synthesis. Island Press, Washington, DC. ISBN: 1-59726-040-1.

[4] (Jacobs, 2011). Jacobs, J. (2011). The Death and Life of Great American Cities (50th Anniversary Edition). Modern Library.

[5] (Armato, 2017). Armato, F. (2017). Pocket Park: Product Urban design. The Design Journal, 20(1), S869-1878. DOI: https://doi.org/10.1080/14606925.2017.1352705

[6] Gabree, J. (1973). Surviving the city. New York, United States: Ballantine Books.

[7] Labuz, R. (2019). Pocket Park - A New Type of Green Public Space in Kraków (Poland). IOP Conference Series: Materials Science and Engineering, 471, 112018. doi:10.1088/1757-899x/471/11/112018

[8] American Society of Planning Officials. (1967). "Vest Pocket Parks" Planning Advisory Service Information. Chicago, Illinois.

[9] Johnson, J., \& Frankel, F. (1991b). Modern Landscape Architecture: The Works of Rut Blees Luxemburg (1st ed.). Abbeville Press.

[10] Bruces, A (Eds). (2017). Pocket Park Design: Solutions for the regeneration of public space in high-density cities. Austrailia: The Images Publishing Book. ISBN: 978-186-470-6598

[11] Goldsteen, B. J., \& Elliot, D. C. (1993). Designing America: Creating Urban Identity. New York: Van Nostrand Reinhold.

[12] (Seymour, 1969). Seymour, W. N. (1969). Small urban spaces: the philosophy, design, sociology, and politics of vest-pocket parks and other small urban open spaces. New York: New York University Press.

[13] Olmos, M. (2008). Pocket park development standard. https://www.visalia.city/civicax/filebank/blobdload.aspx?B1 obID $=4542$

[14] National Recreation and Park Association. (2012). Creating Mini-Parks for Increased Physical Activity. USA https://www.nrpa.org/contentassets/f768428a39aa4035ae55 b2aaff372617/pocket-parks.pdf

[15] Appleton, J. (1996). The Experience of Landscape (Revised ed.). Wiley. ISBN 978-0471962359

[16] Gehl, J. (1987). Life between buildings: Using public space. New York: Van Nostrand Reinhold. ISBN 978-1597268271

[17] Bufi, A. (2019). Exploring the Social, Environmental, and Governance Potentials of Pocket Parks in Dense Residential Blocks of Tirana. Hamburg: HCU Hafen City Universität Hamburg.

[18] Bach, B., \& Pressman, N. (1992). (Climate-sensitive urban space: Concepts and tools for humanizing cities. Delft, Netherlands: Publicatieburo. 
[19] Whyte, W. (1980). Social Life of Small Urban Spaces. Washington: Conservation Foundation. ISBN097063241X, 9780970632418

[20] Armato, F. (2017). Pocket Park: Product Urban design. The Design Journal, 20(1), S869-1878. DOI: https://doi.org/10. 1080/14606925.2017.1352705

[21] Kugler, N. (2017). Perceptions of space in community-organized public places. 4CITIES | ERASMUS MUNDUS.

[22] Co-PLAN, (2012). A guideline for identifying and understanding 'gaps' in your neighborhood and the steps needed in transforming them into Pocket park through Public Private Partnership. Tirane

[23] Deslandes, A. (2013). Exemplary Amateurism: Thoughts on DIY Urbanism. Cultural Studies Review, 19(1), 216-227. DOI: https://doi.org/10.5130/csr.v19i1.2481

[24] Blake, A. (n.d). Pocket Parks, Urban Parks. University of Washington. Washington. Retrieved fromhttp://depts.washi ngton.edu/open2100/pdf/2_OpenSpaceTypes/Open_Space_ Types/pocke

[25] Bende, C., \& Nagy, G. (2016). Effects of community gardens on local society: The Case of Two Community Gardens in Szeged. Belvedere Meridionale, 28(3), 89-105. DOI: https://doi.org/10.14232/belv.2016.3.7

[26] Andersson, E., Barthel, S., \& Ahrné, K. (2007). Measuring social-ecological dynamics behind the generation of ecosystem services. Ecological applications: A publication of the Ecological Society of America, 17(5), 1267-1278. DOI: https://doi.org/10.1890/06-1116.1

[27] Langemeyer, J., Latkowska, M. J., Nicolas Gomez-Baggethun, E., Voigt, A., Calvet-Mir, L., Pourias, J., Camps-Calvet, M., Orsini, F., Breuste, J., Artmann, M., Jokinen, A., Bechet, B., da Luz, P. B., Hursthouse, A., Stepien, M. P., \& Balezentiene, L. (2016). Ecosystem services from urban gardens. In S. Bell, R. Fox-Kämper, N. Keshavarz, M. Benson, S. Caputo, S. Noori, \& A. Voigt (Eds.), Urban Allotment Gardens in Europe (pp. 115-141). Routledge.

https://www.routledge.com/Urban-Allotment-Gardens-in-E urope/Bell-Fox-Kamper-Keshavarz-Benson-Caputo-NooriVoigt/p/book/9781138921092

[28] Prinzessinnengarten. (n.d.). About Prinzessinnengarten. https://prinzessinnengarten.net/about/

[29] Clausen, M. (2017, June 29). Die Laube ist eröffnet / Hier entsteht ein Freiraum. Prinzessinnengarten.https://prinzessi nnengarten.net/die-laube-ist-eroeffnet-hier-entsteht-ein-freir aum/

[30] Citystic. (2018). CITYISTIC. Retrieved 10 22, 2020, from https://www.cityistic.com/blank-9/2018/07/18/Esta-es-Una-
Plaza---This-is-a-Public-Space

[31] Labuz, R. (2019). Pocket Park - A New Type of Green Public Space in Kraków (Poland). Poland: IOP Conference Series: Materials Science and Engineering.

[32] Samir, S. (2020, September 12). Cancerous building on agricultural lands should be curbed in Egypt. Retrieved September 20, 2020, from https://www.egypttoday.com/Art icle/1/91878/Cancerous-building-on-agricultural-lands-sho uld-be-curbed-in-Egypt

[33] Nagati, O. (2018). From Multiple Publics to Just Public: Tactical Art and Design Interventions in Post-Revolution Cairene Public Space [Collection of Essays]. In C. Doherty (Ed.). Where Strangers Meet. Cairo, Egypt: British Council. https://www.britishcouncil.org/sites/default/files/omarnagat i_a 4 digital highres.pdf

[34] Pojani, D., \& Maci, D. (2015). he Detriments and Benefits of the Fall of Planning: The Evolution of Public Space in a Balkan Post-socialist Capital. Journal of Urban Design, 20(2), pp. 251-272. DOI: https://doi.org/10.1080/13574809 .2015 .1009013

[35] Theodori, V., Vaso, A., \& Henna, E. (1995). Status of Public Participation Practices in Environmental Decision making in Central and Eastern Europe: Case studies of Albania, Bulgaria, Croatia, Czech Republic, Estonia, Hungary. Albania: The Regional Environmental Center for Central and Eastern Europe.

[36] Elmqvist, T., Thomas, C. L., Barthel, S., \& Costanza, R. (2013). History of Urbanization and Missing Ecology. In Elmqvist, T., Fragkias, M., Goodness, J., Güneralp, B., Marcotullio, P.J., McDonald, R.I., Parnell, S., Schewenius, M., Sendstad, M., Seto, K.C., \& Wilkinson, C. (Eds.), Urbanization, Biodiversity and Ecosystem Services: Challenges and Opportunities (pp. 13-30). Springer. ISBN 978-94-007-7088-1. DOI 10.1007/978-94-007-7088-1

[37] Banerjee, T. (2001). The Future of Public Space: Beyond Invented Streets and Reinvented Places. Journal of the American Planning Association, 67(1), 9-24. DOI: https://doi.org/10.1080/01944360108976352

[38] Marcus, C. C., \& Francis, C. (1998). People place. Design guidelines for urban open space. New York: John Wiley and Sons.

[39] Grewal, S. S., \& Grewal, P. S. (2012). Can cities become self-reliant in food? Cities, 29(1), 1-11. https://doi.org/10.1 016/j.cities.2011.06.003

[40] Kayden, J. (2013). Creative Cities: Panel 5. https://www.youtube.com/watch? $\mathrm{v}=\mathrm{sKVke} 5 \mathrm{KwLdE} \& \mathrm{t}=8 \mathrm{~s}$

[41] Assaker, D. (2020). Reimagining the Ministries' Quarter of Downtown Cairo (Unpublished master's thesis). RWTH Aachen University. Retrieved November 2, 2020, from https://arch.rwth-aachen.de/go/id/jsyvq?lidx=1 